\title{
Reflecting on the First Two COVID-19 Deaths in Uganda: A Public Health Perspective
}

\author{
Joseph Kawuki ${ }^{1,2^{*}}$, Quraish Sserwanja ${ }^{3}$, Nathan Obore ${ }^{2}$, Zixin Wang ${ }^{1}$, Joseph Tak Fai Lau ${ }^{1}$
}

${ }^{1}$ Centre for Health Behaviours Research, Jockey Club School of Public Health and Primary Care, Faculty of Medicine, The Chinese University of Hong Kong, Hong Kong - SAR, China

${ }^{2}$ Department of Global Health, School of Public Health, Southeast University, Nanjing, 210009, Jiangsu Province, China

${ }^{3}$ Monitoring and Evaluation Department, Doctors with Africa, Juba, South Sudan

\section{Correspondence:}

Joseph Kawuki

Address: Centre for Health Behaviours Research, Jockey Club School of Public Health and Primary Care, Faculty of Medicine, The Chinese University of Hong Kong, Hong Kong - SAR, China and Department of Global Health, School of Public Health, Southeast University, Nanjing, 210009, Jiangsu Province, China

Email: Joseks256@gmail.com

Received: 06.10.2020,

Accepted: 11.01.2021

https://doi.org/10.29333/jcei/10878

\begin{abstract}
COVID-19 being a rapidly evolving pandemic, early lessons from the first deaths must be learnt to help feed into the public health guidelines. This article, therefore, aims to present the first two deaths due to COVID-19 in Uganda and their public health relevance. This is a case study of the first two COVID-19 deaths reported in Uganda, and the events were prospectively documented. The first case was a 34-year-old female and support staff at a health center II. She first presented with COVID-19 like symptoms before dying on $21^{\text {st }}$ July 2020. The second case was an 80 years old female, who also presented with COVID-19 like symptoms before dying on $24^{\text {th }}$ July 2020. The postmortem samples of both cases were confirmed positive for COVID-19. This study identifies a need for timely identification and testing of COVID-19 suspects, strengthening of health center capacity, as well as more awareness for effective prevention and control of COVID-19.
\end{abstract}

Keywords: COVID-19, first death, case study, Uganda, lessons learnt

\section{INTRODUCTION}

Since its emergence in December 2019, the novel Coronavirus disease 2019 (COVID-19) quickly spread globally, creating a pandemic of global threat $[1,2]$. On $11^{\text {th }}$ March 2020, the World Health Organization (WHO) declared COVID-19 a pandemic having spread to over 110 countries and territories $[1,3]$. As per $18^{\text {th }}$ March 2021, 121,858,289 cases and $2,693,445$ deaths had been confirmed globally, with 4,095,103 cases (3.4\%) and 108,885 deaths (2.7\%) reported in Africa [4]. African countries are generally showing much fewer cases compared to other continents; however, their inability to test many people may largely underestimate incidence rates [3]. Uganda reported the first case of COVID-19 on 21 ${ }^{\text {st }}$ March 2020, and as per $18^{\text {th }}$ March 2021, 40,607 cases had been reported with 15,099 recoveries and 334 deaths with 907,398 tests done $[4,5,6]$.

Since March 2020, Uganda put in place different measures to contain the transmission of COVID-19. These included: closure of all international border points including airports for passengers, the closing of schools and places of worship, suspending mass gatherings and public and private transportation, with a nationwide lockdown that was declared on $24^{\text {th }}$ March 2020 [5]. Despite the above control measures in the fight against COVID-19, Uganda reported its first death on $23^{\text {rd }}$ July 2020 [5].

This pandemic has greatly strained the healthcare systems in low, middle and highincome countries [1]. Countries in the SubSaharan region which already face several health challenges such as the limited number of personal protective equipment, human resources and limited access to intensive care units, amongst others, need to strengthen their healthcare systems to fight the COVID-19 pandemic [7]. Uganda is a country with a population of over 40 million people and it currently has a nurse-topatient ratio of $1: 8$, and at the start of the pandemic, it only had 55 intensive care unit (ICU) beds, $80 \%$ of which are in the capital city [7].

COVID-19 being a rapidly evolving pandemic, it is crucial that early lessons from the first deaths are obtained to strengthen the current public health guidelines and 
hence contribute to the country's efforts in containing the pandemic. In this article, we therefore, present the first two deaths related to COVID-19 in Uganda and their public health relevance.

\section{CASE PRESENTATION}

Here we present the first two COVID-19 deaths in Uganda. The data and information were mainly obtained from the Ministry of Health-Uganda website [8], which gives routine updates on COVID-19 in the country. In addition, extra information was sourced from the major national news websites, as they communicate daily nationwide events $[9,10]$.

\section{Case 1}

According to the Ministry of Health $(\mathrm{MoH})$, Uganda registered its first COVID-19 death on $23^{\text {rd }}$ July 2020. This was a 34-year-old female Ugandan and a support staff of Wasungui Health Center II in Namavia sub-county in Namisindwa District. Two weeks before admission, she travelled to a border town (Malaba in Tororo district) for a visit. She was reported to have participated in the community distribution of mosquito nets three days before her admission [6]. Namisindwa district is bordered by Kenya in the east and south, with a lot of illegal border crossings between Uganda and Kenya. The deceased first presented signs and symptoms similar to those of COVID-19, which included; fever, dry cough, headache, and difficulty in breathing [8].

She was initially admitted to the Wasungui Health Center II on Wednesday, $15^{\text {th }}$ July 2020 , and was treated for severe pneumonia. However, on Monday $20^{\text {th }}$ July 2020, she was transferred to Joy Hospice health facility, in Mbale District, where she was isolated in the female ward. While in isolation, the patient's condition deteriorated, presenting with difficulty in breathing, chills, cough, and headache. Unfortunately, she passed away on Tuesday $21^{\text {st }}$ July 2020 at 2:00 am, samples were taken off for further investigation, and she was buried on $23^{\text {rd }}$ July 2020 as per safe, dignified burial procedures [11]. The postmortem samples from the deceased were confirmed positive for SARS-COV-2 by four laboratories; Uganda Virus Research Institute (UVRI), Makerere University laboratory, Tororo laboratory and Central Public Health Laboratories (CPHL). Furthermore, gross anatomy findings at postmortem exhibited features of acute pneumonia, which is consistent with COVID-19 infection [8].

As part of the response, the MoH-Uganda reported that 108 contacts to the deceased had been so far listed and placed under quarantine by the health authorities as of $30^{\text {th }}$ July 2020; in Namisindwa district (76 contacts), Manafwa (11 contacts) and Mbale district (21 contacts). The listed contacts included family members and healthcare workers. Of the samples collected from these contacts, 3 were positive and were all health workers who cared for the deceased while admitted at Wasungui health center II [6]. In addition, the
$\mathrm{MoH}-$ Uganda reported proceeding with vigorous and urgent identification of the source of infection, the possible transmission lines, and the extent of community exposure $[8]$.

\section{Case 2}

According to the MoH-Uganda, the second case was an 80-year-old female, a resident of Mengo, Kisenyi III in Kampala. She was admitted to the Platinum hospital on Friday $24^{\text {th }}$ July 2020 at 5:00 pm after she presented with COVID-19 symptoms of cough, fever, chest pain and difficulty in breathing [9]. She was later referred to Mengo hospital (a tertiary care hospital) for further treatment but unfortunately died at 6:30 pm on the same day. During the admission process at Mengo hospital, the medical team suspected her due to presentation of COVID-19 like symptoms and effectively took the standard operating procedures of handling COVID-19 suspected patients, including isolating her in an Intensive Care Unit. The Mengo hospital team immediately notified the MoH-Uganda and Kampala City Council Authority (KCCA) through the normal channel $[9,10]$.

Following her death, postmortem samples analysed at the Uganda Virus Research Institute, and Makerere University Hospital confirmed positive for SARS-COV-2. The $\mathrm{MoH}$ also reported having initiated contact tracing of all the people who might have come into contact with the deceased. As of $30^{\text {th }}$ July 2020, 75 contacts had been listed, of which 27 were health workers $[6,10]$.

\section{LESSONS LEARNT AND RECOMMENDATIONS}

\section{Timely Screening, Testing, and Diagnosis}

There is a need to ensure that all health workers have the ability to identify COVID-19 suspects, as per the $\mathrm{MoH}$ guidelines. The first case was first admitted at a health facility on $15^{\text {th }}$ July 2020 before she was referred to another health facility on $20^{\text {th }}$ July 2020, without being identified as a COVID-19 suspect. Given the symptoms she presented with, the district response team should have been notified on the first day of admission and relevant precautions like isolation, referral and COVID-19 tests done according to the $\mathrm{MoH}$ COVID-19 guidelines [12]. This would help in early diagnosis, limit the number of case contacts and also enable early initiation of treatment. The second case was initially admitted into a well-equipped and stuffed private hospital located within the capital city and less than 2 kilometres from Mulago National Referral Hospital. However, this patient was still not suspected to have been a potential COVID-19 case despite the typical symptoms and age risk. This could partly be due to inadequate awareness or a low index of suspicion among healthcare providers.

Strengthening the testing services by ensuring increased laboratory coverage is required. At the time of the first two deaths, the country had only 6 accredited COVID-19 testing laboratories. However, as of $18^{\text {th }}$ March 2021, the number had been scaled up to 18 laboratories [6]. The $\mathrm{MoH}$ should 
work towards ensuring that at least every district or region has a laboratory that is able to offer COVID-19 testing services. In the first case, the patient was referred from the Namisindwa district to a health facility in Mbale district. Despite the presence of Mbale regional referral hospital in the district, the COVID-19 tests were only able to be done in the Tororo and Kampala districts. Delayed testing, as noted in the first case, risks further spread of the disease by unknown contacts. Priority and routine testing, preferably with short-turnaround-time (STAT) tests, is essential for real-time patient management and infection control. When other less infectious forms of pneumonia are present, and respiratory isolate resources are scarce there is need for the doctors to have a high index of suspicion especially among the frontline workers working in high-risk locations of the country as they come into direct contact with patients [13].

Furthermore, results from studies done in various countries show that asymptomatic persons are playing a significant role in the transmission of COVID-19. This underlines the need for a change of approach from symptom-based screening, especially among staff at healthcare facilities. If no routine screening is done among healthcare workers and support staff, we may fail to detect infectious cases leading to disastrous results [14].

\section{Strengthening of Health Center Capacity}

The need to ensure that the health workers are able to provide services as per the ministry of health structure is noted. The first case was admitted in a health center II, for over four days, which is not meant for inpatient care. According to Uganda's healthcare system, each district should have a General Hospital, and referral level Health Centre IVs at the county level. Each Health Center IV supervises a number of Health Centre IIIs at a sub-county level, which often have maternal health services in addition to ambulatory care. Below the Health Centre IIIs are dispensaries called Health Centre IIs, at a parish level, that offer outpatient services. At the community level, there are Village Health Teams who provide the day-to-day referral of patients from the community [15]. However, the lack of transportation could partly explain the observed delays in referral, which calls for prioritisation of ambulance services, especially in the high-risk districts.

\section{Improving Healthcare Workers' Capacity}

There is a need to ensure that health facility staff have, and are able to use the necessary information regarding COVID-19 prevention and also ensuring that all staff, including support staff, have the needed personal protective equipment (PPE). The first case was a support staff at a health center II, so there is a possibility that she contracted the virus while at work. The infection and subsequent death of front-line healthcare workers (except infectious disease physicians) maybe because they received inadequate training for Infection Prevention and Control (IPC), leaving them with a lack of knowledge of IPC for respiratory borne infectious diseases [16]. After initiation of emergency responses, healthcare workers and hospital support staff may not have dedicated enough time for systematic training and practice. Professional/ supportive supervision and guidance, as well as monitoring mechanisms, should be improved in both Government and Private facilities nationwide to avoid amplifying the risk of infection for healthcare workers. Recommendations such as traffic control bundling and Systems Engineering Initiative for Patient Safety (SEIPS) model in which patients move along routes other than those taken by all healthcare workers and support staff should be considered [17].

\section{Community Awareness}

A need to strengthen and continue community sensitisation and awareness about the dangers of COVID-19 has also been noted. In the first case, the government officials had to be involved in order to stop the locals from attending the burial [18]. This shows that the community still needs to be sensitised to ensure social and behaviour change. Furthermore, most of the locals that had contact with the deceased deserted their homes for fear of being quarantined [18]. This risks further spread of the disease. The $\mathrm{MoH}$ needs to continue awareness about the public health significance of quarantine and ensure that the services and conditions in the quarantine centers are also improved.

Since Uganda is now in the stage of the epidemic that is characterised by community transmission of the virus, the postponement of school terms, the cancellation of mass gathering activities and other measures aimed at reducing the movement of people is still required as the quest for solutions goes on the control. As lockdowns and physical distancing measures are eased, case detection, proactive surveillance, and contact tracing with isolation will be required to prevent a dramatic resurgence of COVID-19 cases [19]. In addition, the region-specific epidemiologic trend of Covid-19 in Namisindwa District and other highrisk districts needs to be investigated in order to prevent large scale community transmission in these areas.

\section{LIMITATIONS}

There was lack of access to detailed information about the cases described, for example the exact days when the cases started getting signs and symptoms, medical procedures done on admission, as well as other clinical information. This could have affected the precise evaluation of these two COVID-19 cases.

\section{CONCLUSIONS}

This case study has presented the first two COVID-19 deaths in Uganda, reflecting on their public health importance and insights gained. The study has noted that there is a need for more effective screening. In addition, timely testing and diagnosis of suspected cases as well as more strengthening of the health facility capacity through more laboratories are required. The need to improve healthcare workers' capacity as well as increased awareness 
of the community are also highlighted for effective prevention and control COVID-19 in Uganda.

Author contributions: All authors have equally contributed to this study, and have all read and approved the final manuscript. All authors concur with the submission.

Funding: This research did not receive any specific grant from funding agencies in the public, commercial or not-for-profit sectors.

Declaration of interest: The authors declare that they have no known competing financial interests or personal relationships that could have appeared to influence the work reported in this paper.

Consent to participate and ethical considerations: Since the study used secondary data, the participants' consent to participate was waived by the ministry of health Uganda. In addition, there was no serious ethical issues involved since no direct interaction of human nor animal specimens were involved.

Acknowledgements: We thank the Ministry of Health Uganda for making the COVID-19 data and information available on its website, which was used for this study.

Data availability: All the data used in this study is contained within the manuscript and can be freely obtained from the referenced online data bases.

\section{REFERENCES}

1. Rutayisire E, Nkundimana G, Mitonga HK, et al. What works and what does not work in response to COVID19 prevention and control in Africa. Int J Infect Dis. 2020; 97: 267-9. doi: 10.1016/j.ijid.2020.06.024.

2. Lounis M. A Descriptive Study of the Current Situation of COVID-19 in Algeria. Electron J Gen Med. 2020; 17(6): em253. doi: 10.29333/ejgm/8287.

3. Kobia F, Gitaka J. COVID-19: Are Africa's diagnostic challenges blunting response effectiveness? AAS Open Res. 2020; 3: 4. doi: 10.12688/aasopenres.13061.1

4. Worldometer. Coronavirus Update (Live): Reported Cases and Deaths by Country, Territory, or Conveyance. Available at: www.worldometers.info/coronavirus/ (Accessed: 18 March 2021).

5. Ministry of Health Uganda: Coronavirus (pandemic) Covid-19. Available at: http://www.health.go.ug/covid (Accessed: 30 July 2020).

6. Ministry of Health Uganda. Update on COVID-19 Response in Uganda. Available at: https://www.health. go.ug/cause/update-on-covid-19-response-in-uganda/ (Accessed: 01 August 2020)

7. Nuwagira E, Muzoora C. Is Sub-Saharan Africa prepared for COVID-19? Trop Med Health. 2020; 48: 18. doi: 10.1186/s41182-020-00206-x.

8. Ministry of Health Uganda. Update on the Outbreak of COVID-19 in Uganda. 2020. Available at: https://www. health.go.ug/cause/update-on-the-outbreak-of-covid19-in-uganda/ (Accessed: 28 July 2020).
9. Okoth C. Uganda registers second COVID-19 death. 2020. Available at: https://www.newvision.co.ug/news/ 1523414/uganda-registers-covid-19-death (Accessed: 28 July 2020).

10. Bwire J. Uganda confirms second Coronavirus death. 2020. Available at: https://www.monitor.co.ug/News/ National/Uganda-confirms-second-Coronavirusdeath/688334-5599514-yb998cz/index.html (Accessed: 28 July 2020).

11. Ministry of Health Uganda. National Guidelines for Management of COVID-19. 2020. Available at: https://www.health.go.ug/cause/national-guidelinesfor-management-of-covid-19/ (Accessed: 1 August 2020).

12. Tang YW, Schmitz JE, Persing DH, et al. Laboratory diagnosis of COVID-19: current issues and challenges. Journal of clinical microbiology. 2020, 26 May; 58(6): e00512. doi: 10.1128/JCM.00512-20.

13. Huff HV, Singh A. Asymptomatic transmission during the COVID-19 pandemic and implications for public health strategies. Clinical Infectious Diseases. 2020, 28 May: ciaa654. doi: 10.1093/cid/ciaa654.

14. Wang J, Zhou M, Liu F. Reasons for healthcare workers becoming infected with novel coronavirus disease 2019 (COVID-19) in China. J Hosp Infect. 2020, 6 March: 1051. doi: 10.1016/j.jhin.2020.03.002.

15. Malish JP. A Critical Evaluation of the Effectiveness of the Healthcare System in Uganda, 1987 to 2015. Available at: SSRN 3132246. 2017 21st August. doi: $10.2139 /$ ssrn. 3132246.

16. Schwartz J, King CC, Yen MY. Protecting healthcare workers during the coronavirus disease 2019 (COVID19) outbreak: lessons from Taiwan's severe acute respiratory syndrome response. Clinical Infectious Diseases. 2020; 71(15): 858-60. doi: 10.1093/cid/ciaa255.

17. Gan WH, Lim JW, David KO. Preventing intra-hospital infection and transmission of COVID-19 in healthcare workers. Safety and Health at Work. 2020, 24 March; 11(2): 241-3. doi: 10.1016/j.shaw.2020.03.001.

18. The Observer. Fear grips Namisindwa as Uganda's first coronavirus victim gets buried. Available at: https://observer.ug/news/headlines/65813-fear-gripsnamisindwa-as-uganda-s-first-coronavirus-victimgets-buried (Accessed: 29 July 2020).

19. Salathé M, Althaus CL, Neher R, et al. COVID-19 epidemic in Switzerland: on the importance of testing, contact tracing and isolation. Swiss medical weekly. 2020; 150(11-12): w20225. doi: 10.4414/smw.2020.20225. 